Annales UMCS

Informatica

Lublin-Polonia

Sectio AI

http://www.annales.umcs.lublin.pl/

\title{
The hierarchical system of distributed objects work control
}

\author{
Dariusz Bober* \\ Institute of Computer Science, Lublin University of Technology Nadbystrzycka 36B, \\ 20-618 Lublin, Poland
}

\begin{abstract}
The common attribute of the geo-distributed systems (GS) is the way of their organization. The structure of GS is usually an up-down depended hierarchy where the processes of their inter work control are implemented as two sides (up-down, down-up) information exchange. As a result, the subcomponents of typical GS are in some distance from each other. The main clue of GS manager is the quality of information process flow and a medium of data exchange. The state of art of data describes technologies, e.g. XML (eXtensible Markup Language) $[\mathbf{1}, \mathbf{2}, \mathbf{3}]$ and the progress of the Internet interoperabilitation, especially in Web Services [4], gives for the designers some new opportunities of application design. In this way, the layer of data interchange of GS subcomponents will migrate to the next/new level of abstraction. Its consequence is ability of reorganization of the controlled object structures and modelling of dimensions extends.

This article presents a model of hierarchical system of distributed objects work control (HCS). The model is based on a cube of data repository and dedicated web serviced methods. This model is used in the investigations of the electric energy consumption control by the author.
\end{abstract}

\footnotetext{
*E-mail address: borowik@pluton.pol.lublin.pl
} 


\section{Introduction}

If we study the domain of most physical objects and organizations, whose structures are geo-distributed systems (GS), we could recognize that the common attribute of these systems is: the hierarchical structure of their work control and/or management. The distributed systems are usually organized as the hierarchies of up-down depended levels of decision taking, where the process of work control is implemented as two sides (up-down, down-up) information exchanging. Usually the functions of the exchanged data are included in two types of classes:

- managing: the decisions of the head of an organization are exchanging from up to down as the coordinates and redistributing to dependent nodes;

- controlling: the data of an organization state of work is exchanged from down to up and is aggregated on each level of a hierarchy.

The experience shows that the well organized processes of a data flow are one of the main conditions of the organization success. From the point of view of the data flow process inter distributed objects, the mechanism of data exchanging usually looks similarly: one of the nodes corresponds to the other in the hierarchy of the objects using an accessible medium for the data exchange. Only the medium of the data exchange changes in the history but the mechanism remains unchanged. Currently, the state of art of telecommunication technology gives almost unlimited possibilities for the data exchange $[\mathbf{1}, \mathbf{2}, \mathbf{3}]$. By implementing the EDI (Electronic Data Interchange) functionality $[\mathbf{5}, \mathbf{6}]$ for the data flow process, it is possible to improve the object subcomponents interoperability and in consequence, it allows to develop the mechanism of auto control of the whole structure of the object on each level of it is hierarchy.

An example of GS object is the electric energy distribution system (SE). The SE's structure (see Fig. 1) on one hand depends on the number of energy generators and on the other hand the number of consumers. As it has been shown in $[\mathbf{7}, \mathbf{8}]$, both sides of dependent energy market players are dependent on each other because of the nature of the electric energy, where the consumers cannot consume more energy than the generators are able to generate and on the other hand, the generators cannot supply more energy than the consumer's demand. The thesis of the author investigations is that "Implementation of electronic data interchange instruments for the data exchange between the users of the electro energetic system improves its own management and the energy consumption prediction". And here the hierarchical system of distributed objects work control (HCS) is precise for the electric energy distributor needs $[\mathbf{9}, \mathbf{1 0}, \mathbf{1 1}]$. 


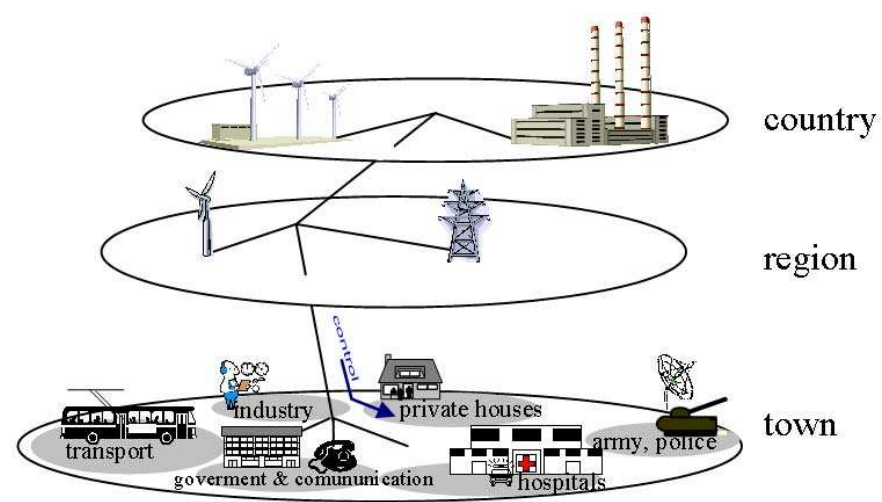

Fig. 1. Typical hierarchy of electric energy distribution system

In fact, the model of HCS could be used for each of the GS objects as well, e.g. carbon dioxide polluting system, system of soil fertilization or system of early dangerous warning. The domain of these solutions is the nature of knowledge which depends on data being probed by many nodes of the lowest layer of a hierarchy and the knowledge grows by the aggregating methods on each layer of the structure.

\section{Conception of hierarchical control system}

From the point of view of the HCS system each of the GS objects could be decomposed into many separate nodes, between the nodes there exist some branches of dependences and of the data exchange directions. The HCS data repository has to evidence information about each node of the GS and their branches. The state of art of the data base engineering [12] shows that information about an object is evidenced in the field of a table and it is usually the name of the field which corresponds to the name of the object attribute. The number of attributes (fields) corresponds to the necessity of complete controlled process description. Although it could be differenced in type and number of the attributes between the nodes of different levels of the hierarchy. Moreover, there are many differences in type and quantity of node attributes of different GS structures.

The HSC data repository is open to those differences and it is able to describe each known data type of the node attributes (see Fig. 2) and to define as many of the node attributes as it is necessary. The number of the attributes of any node, evidenced in the HSC system, counts $n+4$, where $n \in N$. The first four of the attributes are mandatory, the next are obligatory because the HSC system functionality allows to determinete any hierarchical structure by its user, not a programmer. 
The structure of any GS system is defined in two steps. In the first one the user determines the number of the levels of the structure hierarchy. In that point he has to define the attributes of each level node. The mandatory attributes construct hierarchy by describing the name of the level of hierarchy (node_name), the position in the hierarchy (parent_id), the structure of the node belongs to (structure $i d$ ) and it gives the node unique identification (node $i d$ ). The optional attributes allow to determine any kind of information to be evidenced on the current level of the hierarchy. To add a new attribute of the node, the user ought to define: name of attribute, type of data being stored, measure of unit, flag of mandatory, flag of aggregates. The flag of aggregates tells the HCS system that some data on one level nodes has to be aggregating to the other one.

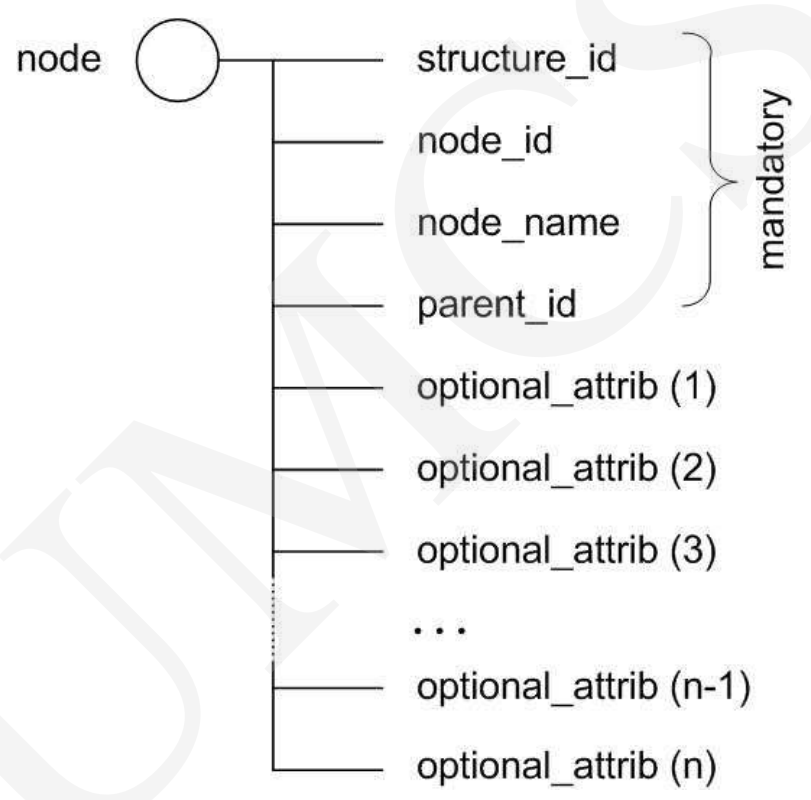

Fig. 2. The GS's node repository in the HCS's database

After the hierarchy determination the user could define the whole structure tree of the object (see Fig. 3). The user is asked to add as many nodes on each level of the hierarchy as he needs, but in this step he got all types of the attributes of each node of each level defined and only what he has to do is to input values of those attributes.

This segmentation of the structure definition steps allows to separate the roles of HCS system users. The first role, the administrator of structure role, is responsible for the definition of the structure mission - e.g. what kind of data on each level of the hierarchy will be collected and how many levels of the 


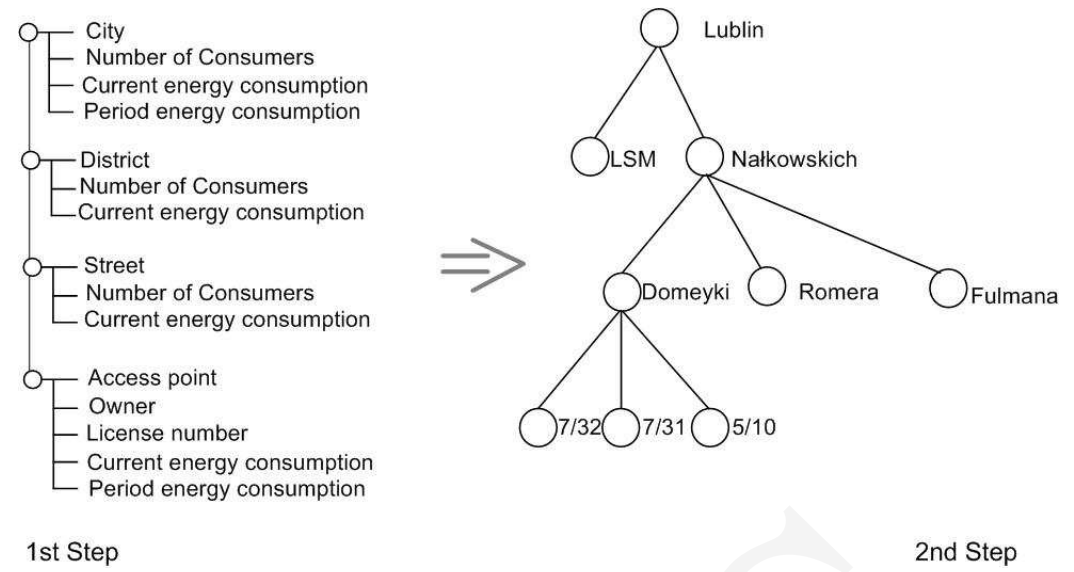

Fig. 3. Steps of structure definition

hierarchy he plans to administrate. The second role could be represented by many other users of the controlled object. The users are able only to log into the HCS system, and to register their own nodes in the hierarchy of the object structure. They are limited only to access the levels where they are placed in.

The next very powerful functionality of the HCS system is the way of intercommunications between the nodes. Each node exchanges the data with its parent node by asking him through some dedicated web services methods. Each node exchanges the data with its sons by the fact that he is asked by the sons (see Fig. 4). Because the communication between the nodes is implemented as a web service method there is no doubt that one node of the hierarchy is stored in one local data repository of the HCS system and the other one is stored in a remote data repository. The only one condition to interoperate the geo-distributed subcomponents of the GS system is their ability to process this type of methods. In the simplest way it could be implemented as a web form interface (see Fig. 4), where the data will be input by the end users $[\mathbf{4}, \mathbf{1 3}, \mathbf{1 4}]$.

The intelligent units of the lowest level of the hierarchy are the fundamental condition to implement full interoperability of the XML technology in such a distributed object as the electric energy distribution system [10]. If this elaboration finds some interest of the potential users and/or investors, then the appropriate functionality of intelligent measure units are implemented into most of the electronic equipment of intelligent buildings [15]. It is granted that the web service method will be used for the communication by a cube repository of the HSC system and by an electronic measure unit as well (see Fig. 4).

By using the web service methods for the communication process there is no difference between two events: 


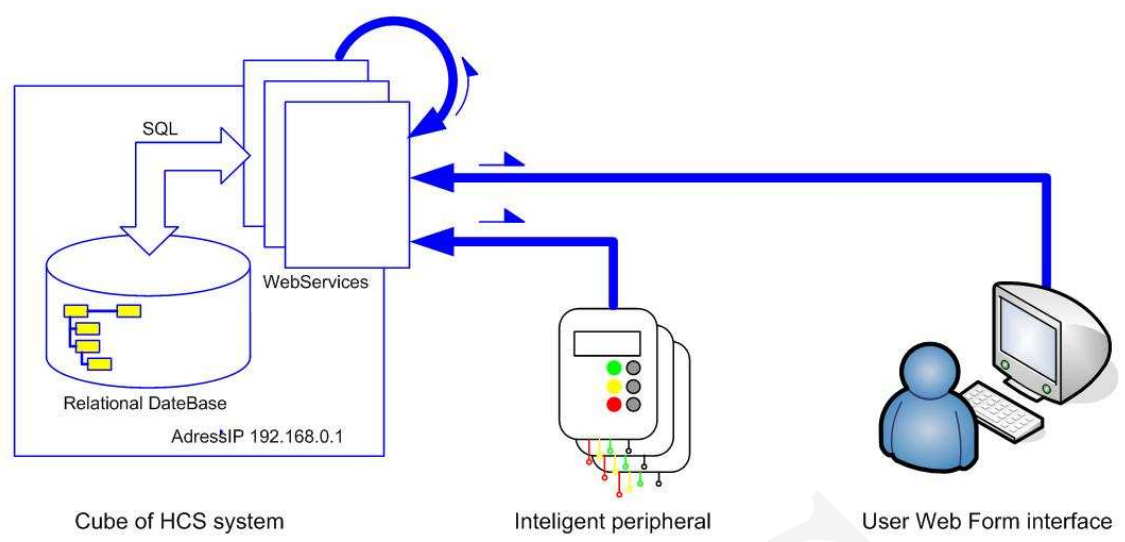

Fig. 4. Inter HSC system communication between the nodes of GS objects

- a method could be called/run by an intelligent peripheral or the end user, but it could be called/run by the other cube of the HCS system as well. So, we could configure many cubes of the HCS in different localization and in this way some geo-distributed process could be controlled by the geodistributed cubes of the HCS. This ability of the HCS system is attractive especially from the scientific centers point of view, which could coordinate their explorations of some geo-distributed problems/research, e.g. pollution of rivers in central-east Europe.

- a node asking its father for directions, could take this data from a local cube and from remote ones as well (see Fig. 5). So, behind the geo-distributed object being controlled and the geo-distributed cubes of the HSC system we have the geo-distributed data base which is the repository of the whole structure information.

The conception of the Hierarchical Control System for the geo-distributed objects work control presented in this paper is still in the process of the author's investigation. Although some partial functionality of the HSC was implemented into practice in the last semester of students' laboratory classes the source of the example of $\mathrm{C \# .Net} \mathrm{application} \mathrm{is} \mathrm{published} \mathrm{by}[\mathbf{1 6}]$.

\section{An example of dispersed object to be controlled}

One of the possibilities to put the HSC system into practice is to use it for coordination of work of the Electric Energy System (SE) [7, 10, 13, 14]. The author, in his dissertation about the new method of control of electric energy consumption [17], presents a model of the hierarchical control system 


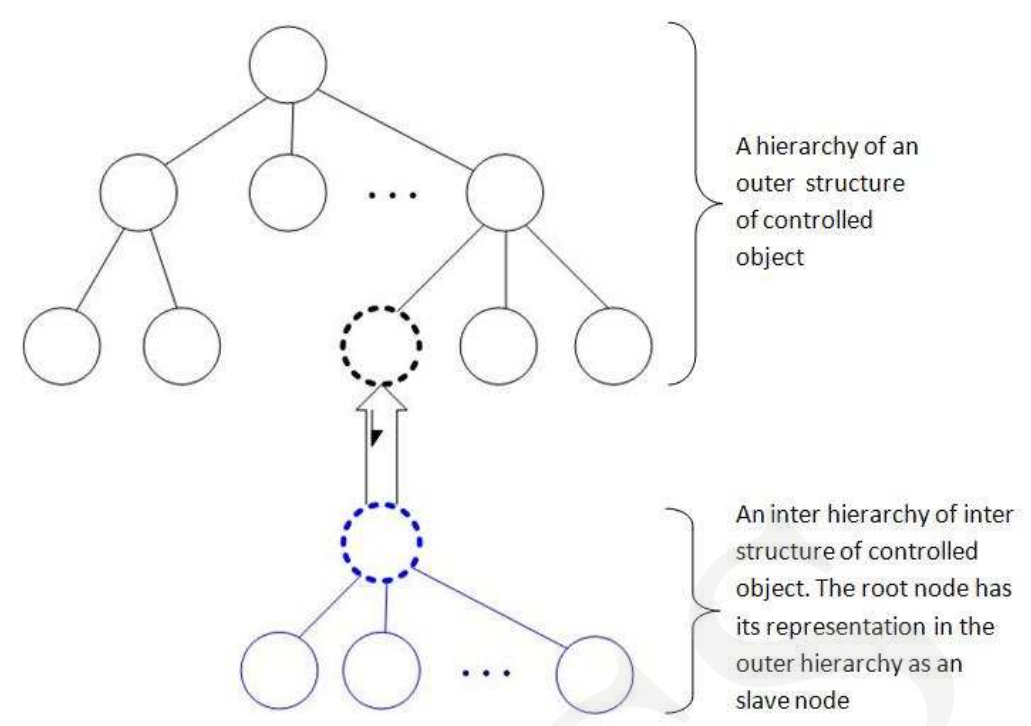

Fig. 5. Geo-distributed data repository and geo-distributed hierarchy of GS

and implies that it is one of the conditions of correct methods for the nodes of the EE distribution net interoperation.

Figure 6 presents a conception of the whole SE distributors work coordination by implementation of the cube of the HCS system in each localization of the distributor Head Office, and by aggregating the information about the energy consumption of the whole country. It could be a future hypothetical situation, although in the current stage of the author's investigation the hierarchical control methods are verified in the Matlab's environment for one of the Polish distributors $[\mathbf{1 7}]$ and it could be implemented as part of that system.

By implementing the Power Modes model [18] for powering the electric energy customers and with controlling the consumption by the Hierarchical Control System, it is possible to manage the work of the electric and energetic system on each level of its hierarchy. The Power Modes model tells the operators what part of the energy consumption could be limited at current time and by the HSC methods this information will be aggregated on each level of the controlled structure (see Fig. 7).

The results of the author's investigation of the Power Mode model abilities in the situation of a lack of electricity show that the model is helpful in the operational management of the energy consumption process. The model implemented into the Matlab environment was tested on the historical data of 2007 for the consumers of one of the Polish electric power distributors. The structure of the distributor power grid has been reduced into the hierarchy presented in 


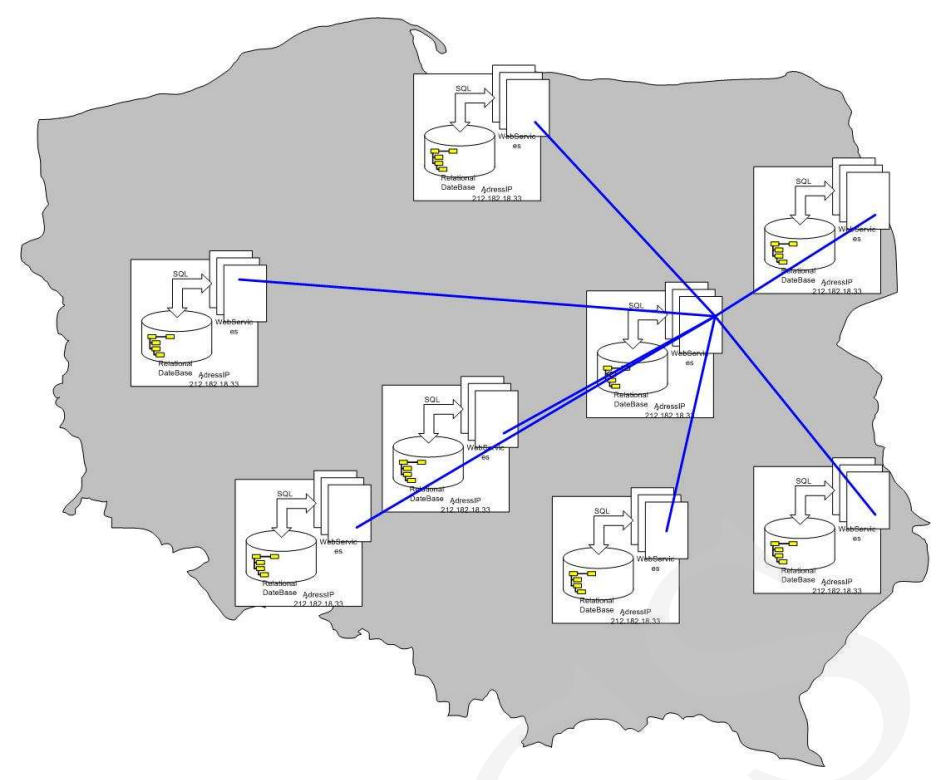

Fig. 6. HCS functionality for the Electric Energy Distributors work coordinate

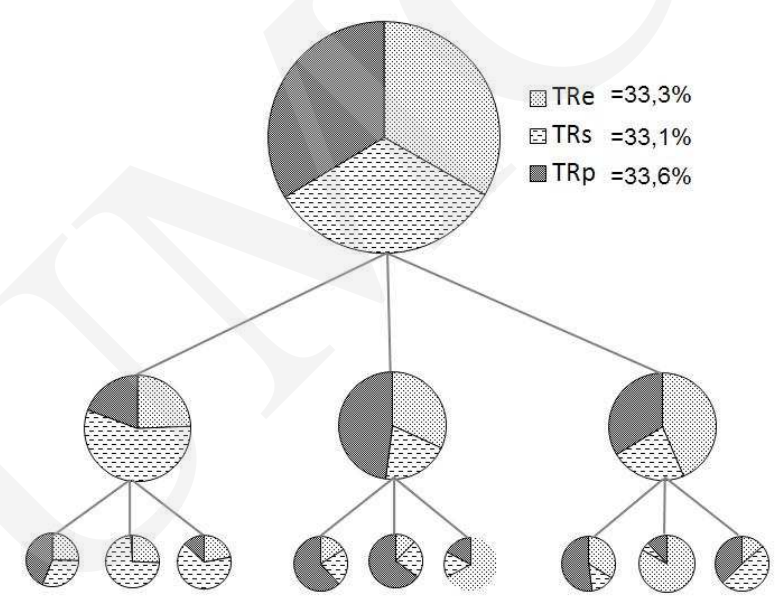

Fig. 7. The Power Modes in the hierarchy of electric energy distribution net

Fig. 8. Using that model some selected HCS methods of the information interchange were simulated. As a result of the research we could compare the graphs in Figs 9 and 10, where the states of the controlled object are presented. Fig. 9 shows the figures of the energy misfit of the customer demand and the distributor supply before the model implementation. In Fig. 10 there are presented the same data but with full implementation of the model in the structure hierarchy of the object. 


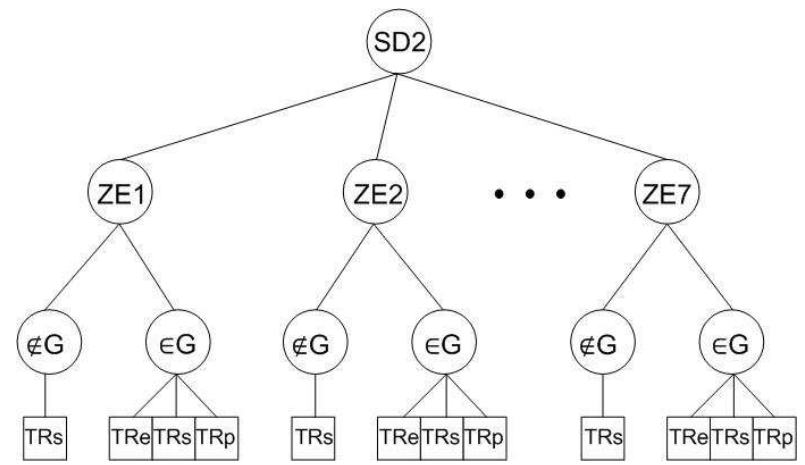

Fig. 8. The structure of controlled object; SD2 - main node which represents the whole power demand of the distributor's power grid; ZE1, ZE2, ..., ZE7 - the geographical area of the distributor is divided into seven subareas of the divisions; in each subarea ZE there are some consumers powered in household tariffs $\in \mathrm{G}$ and some consumers which are powered in other tariffs $\notin \mathrm{G}[\mathbf{1 7}]$

On the lowest level of the object hierarchy (Fig. 8) there was simulated the implementation of the Power Mode (TR) model. Although the nodes $\in \mathrm{G}$ have implemented the full TR model, but for customers who do not belong to $\mathrm{G}$ tariff, they have simulated only the standard $\mathrm{TR}_{s}$ powering mode. The figures of the object state are: TR - id's of ZE nodes where the TR model was implemented; $\Sigma u \in \mathrm{G}$ - the number of households where the TR model is implemented; avPr the average power demanded by households powered in the TR model; $\mathrm{E}(\mathrm{Pr}, \mathrm{T})$ - the total energy consumed by households powered in the TR model in the period of the whole year; $q$ - the number of situations where the supplied power does not balance the demand of the consumers, in this situation it is necessary to buy some more energy/power from the generators; avPn - the average power misfit; $\mathrm{E}(\mathrm{Pn}, \mathrm{q})$ - the total energy misfit.

In paper [19] there are presented numerous examples of the object state in different configurations of the TR model implementation and the HCS methods for data exchange. Here is presented one of the final results of the HCS system data processing and simulations of the object state (see Fig. 10).

As we can see the controlled figures of the object state were improved by Power Mode model implementation and with coordination of the data exchange between levels of the object hierarchy by the proposed methods.

\section{Conclusions}

The functionality of the Hierarchical Control System presented in this paper is responsible only for the proper information interchange between the dispersed subcomponents of the controlled object. The HCS system does not care what 


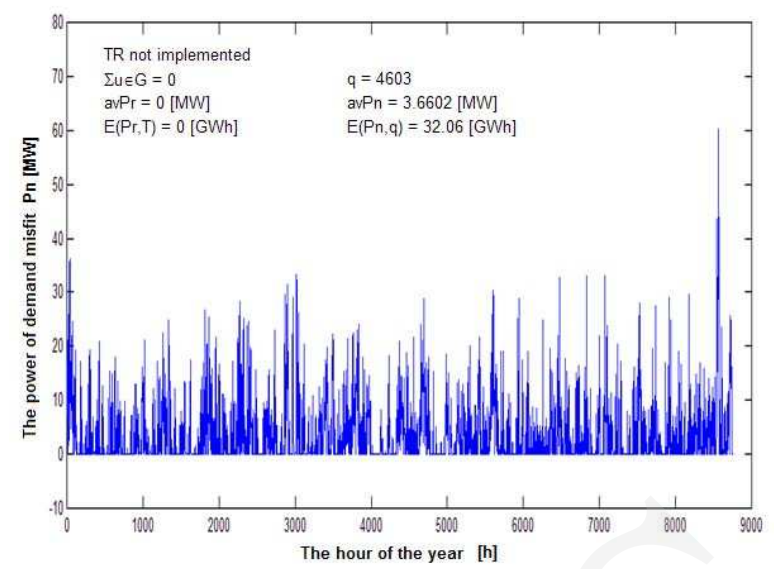

Fig. 9. The state of the object before Power Modes model implementing [17]

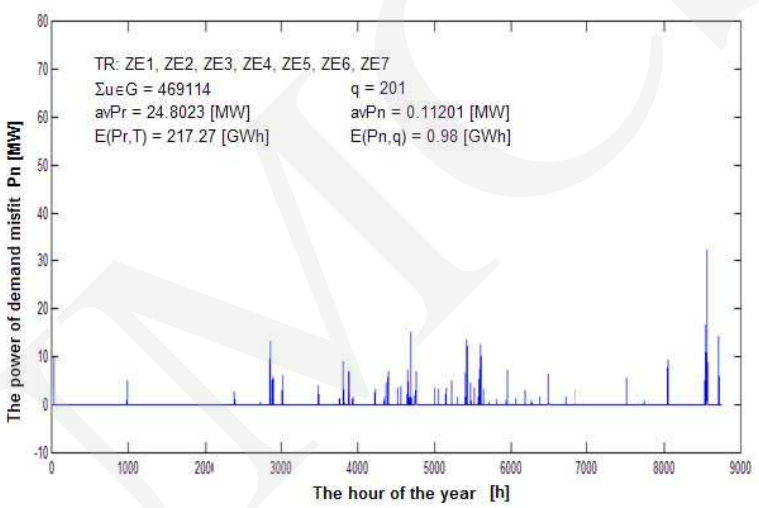

Fig. 10. The state of the object before Power Modes model implementing [17]

node will do with the information delivered using the HCS methods. The decision of the information processing into the tasks stays still on independent sides of the nodes. The nodes make the decision by themselves and the HCS system only exchanges the information about the parameters of the controlled object changes. The logic of the intelligent peripheral will use the HCS system data interchange functionality, and in this way, it will realize the concept of the distributed interoperabilitation. The example presented in section 3 shows that the proposed solutions are helpful for resolution of the problem of energy misfit in the electrical energy distribution system. 


\section{References}

[1] Bober D., Muryjas P., Aspects of XML Technology in eBusiness Transactions, 4th International conference of PHD students, Engineering Sciences I, University of Miskolc, Hungary (2003) 275.

[2] Bober D., Łagód G. and Suchorab Z., Using New Technologies of Computing In Sustainable Development, In. Environmental Engineering Studies, Polish Research on the Way to the EU, Plenum/Kluwer, N.York (2003) 377.

[3] Bober D., XML In Business tasks realisation, Annales Informatica UMCS, Lublin (2004) 357.

[4] Bober D., Kawiak M., Dynamiczne raportowanie w technologii Web-Services, Miłosz M. (red): Systemy mobilne - od teorii do praktyki, PTI, Warszawa 2007, 181.

[5] Muryjas P., Bober D., ebXDI - technologia EDI za rozsagdne pienigdze, Wdrażanie $i$ eksploatacja systemów informatycznych, PTI, Lublin (2002) 85.

[6] Bober D., XML/EDI - elektroniczna wymiana dokumentów biznesowych w oparciu o technologie XML, Miłosz M. (red) Eksploatacja systemów informatycznych - od teorii do praktyki Mikom, Warszawa 2004, 147.

[7] Bober D., Wptyw dwukierunkowej transmisji danych na wygtadzanie krzywej popytu na energię elektryczna, W: Rynek Energii 2(69), kwiecień 200719.

[8] Gładyś H., Malta R., Praca elektrowni w systemie elektroenergetycznym, WTN, Warszawa 1999.

[9] Topolski J., Begier P., Poszukiwanie nowych rozwiazań modelu ryku energii elektrycznej, Wokół Energetyki 8 (2005) 31.

[10] Bober D., The XML Interoperability and the Polish Energy Market Needs, Annales UMCS Informatica AI 5 (2006) 249.

[11] Gawin R., Opomiarowanie odbiorców a liberalizacja rynku energii elektrycznej, Biuletyn Urzędu Regulacji Energetyki 6 (2005).

[12] Lonely K., Oracle Database 10g. The Complete Reference, Helion, Gliwice 2005.

[13] Bober D., Conceptual Model of Informatic System of Control for the Electrical Industry, International Workshop Control and Information Technology, Ostrava, Czech Republic, (2005) 151.

[14] Bober D., Projekt podsystemu informatycznego w zabezpieczeniach systemów energetycznych, Współczesne Technologie Informatyczne, inżynieria oprogramowania, systemy baz danych, Mikom, Warszawa 2005127.

[15] Sroczan E., Nowoczesne wyposażenie techniczne domu jednorodzinnego. Instalacje elektryczne, Państwowe wydawnictwo rolnicze i leśne, Poznań 2004.

[16] Kaczmarski P., Struktury hierarchiczne, Projekt programistyczny realizowany w ramach zajęć laboratoryjnych w Instytucie Informatyki PL w semestrze zimowym 2008. $<$ http://aspspider.info/pakkpl/index.aspx>, 10.02.2008.

[17] Bober D., The electric energy consumption control in the situations of power deficit, Rynek Energii 1(III) (2009).

[18] Bober D., The Electric Energy Customer Powering by Power Modes, Rynek Energii 1 (2008)

[19] Bober D., The Hierarchical System of The Electric Energy Consumption Control, PHD dissertation, Lublin University of Technology 2008. 